\title{
Tuberculosis en cavidad oral con diseminación pulmonar y meníngea
}

\section{Tuberculosis in the oral cavity with pulmonary and meningeal dissemination}

\author{
Jesús Enrique Núñez, Diego Fernando Salinas, \\ Fernando Bolaños, María Fernanda González, \\ Jessica Natalia González • Neiva (Colombia)
}

\section{Resumen}

Objetivo: presentar una de las formas más atípicas de presentación de tuberculosis con inicio en cavidad oral y diseminación pulmonar y meníngea en una mujer no inmunocomprometida cuyo único factor de riesgo exposicional conocido fue la realización de exodoncia.

Caso clínico: caso de mujer adulta joven que secundario a exodoncia presenta lesión ulcerada en cavidad oral, crónica, asociada a pérdida de peso y síntomas constitucionales, sin fiebre.

Consultó en múltiples oportunidades a centros de salud con variados tratamientos, incluyendo antibióticos por tiempo prolongado, sin mejoría.

Consulta a nuestra institución donde de manera incidental se documentan opacidades pulmonares difusas asociadas a deterioro de la conciencia, postración en cama y fiebre.

Se documentó por histología y reacción en cadena de la polimerasa (PCR) de biopsia en cavidad oral, Mycobacterium tuberculosis; con cultivo positivo para el mismo microorganismo en líquido cefalorraquídeo, documentándose caso de tuberculosis primaria en cavidad oral con diseminación pulmonar y meníngea en paciente cuyo único factor de riesgo conocido fue la presencia de una exodoncia.

Conclusión: la tuberculosis primaria de cavidad oral es un tipo infrecuente de presentación de tuberculosis, sugiriendo ante una lesión crónica en mucosa oral, el considerar como diagnóstico diferencial la tuberculosis, incluso ante la ausencia de factores de riesgo como inmunosupresión.

Palabras clave: tuberculosis, mucosa de la boca, úlcera, extracción dental.

\section{Abstract}

Objective: to present one of the most atypical forms of presentation of tuberculosis with onset in the oral cavity and pulmonary and meningeal dissemination in a non-immunocompromised woman whose only known exposure risk factor was the performance of exodontia.

Clinical case: case of a young adult woman who after exodontia presented a chronic ulcerated lesion in the oral cavity associated with weight loss and constitutional symptoms, without fever.

She consulted multiple times to health centers with varied treatments, including antibiotics for a long time without improvement, and then consults our institution where incidentally diffuse pulmonary opacities associated with deterioration of consciousness, prostration in bed and fever, are documented.

Histology and polymerase chain reaction (PCR) of oral cavity biopsy showed Mycobacterium tuberculosis with positive culture for the same microorganism in cerebrospinal fluid, documenting the case of primary tuberculosis in the oral cavity with pulmonary and meningeal dissemination in a patient whose only known risk factor was the presence of an exodontia.

Conclusion: primary tuberculosis of the oral cavity is an infrequent type of tuberculosis, but in the presence of a chronic oral mucosal lesion tuberculosis as a differential diagnosis should be considered, even in the absence of risk factors such as immunosuppression.

Keywords: tuberculosis, oral buccal mucosa, ulcer, dental extraction.

Dr. Jesús Enrique Núñez Renza: Residente de Medicina Interna; Dr. Diego Fernando Salinas Cortés: Internista Infectólogo. Profesor de Medicina Interna e Infectología, Universidad Surcolombiana; Dr. Fernando Bolaños: Patólogo Hospital Universitario Hernando Moncaleano Perdomo; María Fernanda González y Jessica Natalia González: Estudiantes de Medicina, Hospital Universitario Hernando Moncaleano Perdomo. Neiva (Colombia).

Correspondencia: Dr. Jesús Núñez Renza. Neiva (Colombia).

E-mail: jebus8202@hotmail.com 


\section{Introducción}

La tuberculosis de cavidad oral es una de las formas más atípicas y menos común de presentación de la tuberculosis, generalmente se debe a diseminación hemática o linfática y el origen en la mayoría de ocasiones es secundaria a una infección pulmonar $(1,2)$.

El presente caso tiene como objetivo dar a conocer las manifestaciones clínicas de una forma atípica de presentación de tuberculosis primaria en cavidad oral con diseminación pulmonar y meníngea de una patología prevalente en nuestro medio que ocasiona gran morbilidad, mortalidad, discapacidad y gastos elevados al sistema de salud.

\section{Descripción del caso}

Mujer de 29 años sin antecedentes previos, admitida a nuestra institución por presentar lesión ulcerada en cavidad oral asociada a síntomas constitucionales. Seis meses previos al ingreso se había realizado una extracción dental (diente número 26) después de lo cual según la paciente presenta una lesión ulcerada de bordes irregulares de 1 x $1 \mathrm{~cm}$ no dolorosa a la palpación (Figura 1).

Se acompaña de pérdida de $15 \mathrm{~kg}$, astenia, adinamia, hiporexia marcada, sin fiebre $u$ otros datos asociados, con consulta en diferentes oportunidades y varios tratamientos, entre ellos antibióticos orales, sin mejoría.

$\mathrm{Al}$ ingreso se observa paciente postrada en cama, caquéctica, afebril con signos vitales dentro de límites normales, se apreció la lesión descrita en cavidad oral sin dolor a la manipulación, sin secreción, con adenopatías cervicales izquierdas móviles, no dolorosas a la palpación, sin otro compromiso en el resto del examen físico.

Se realizaron estudios de laboratorios generales documentándose: anemia normocítica normocrómica, prueba de ELISA para HIV negativa, sin otras anormalidades llamativas.

Al segundo día del ingreso manifiesta disnea que se hace progresiva asociada a fiebre, se realiza radiografía de tórax con

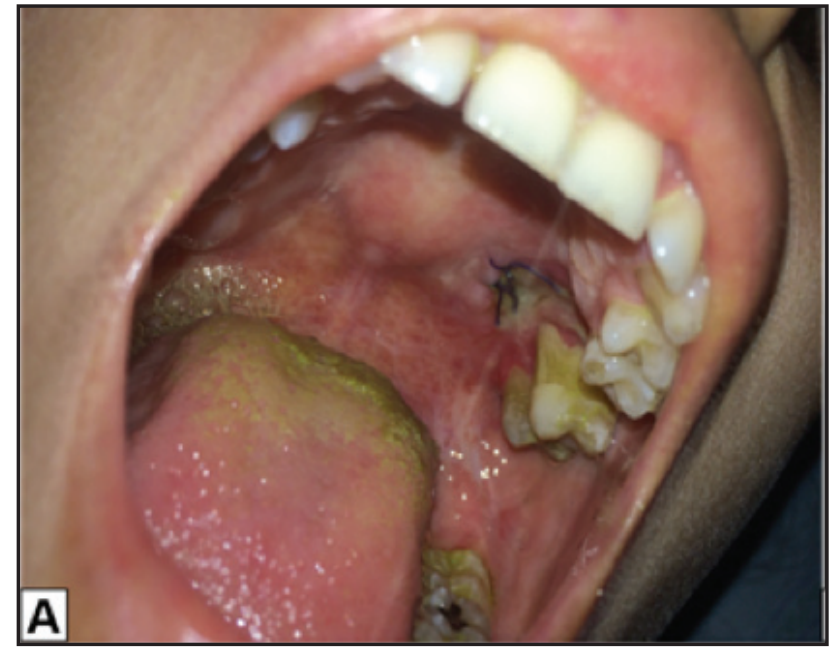

Figura 1. Lesión ulcerada en cavidad oral. evidencia de campos pulmonares expandidos con presencia de infiltrado retículo - granulillar difuso diseminado hacia ambos campos pulmonares, todo esto en posible relación a enfermedad intersticial difusa crónica (Figura 2).

Basados en estos hallazgos se considera alta sospecha de enfermedad granulomatosa versus neoplásica con foco primario en cavidad oral por lo cual se realiza biopsia de la lesión y se inicia tratamiento antituberculoso de forma empírica.

Se realizan estudios de baciloscopia (3) los cuales se reportan negativas.

En el día cinco de hospitalización la fiebre persistía con mejoría de la disnea y esta vez asociada a deterioro de la conciencia manifestada por somnolencia persistente, se realiza tomografía de cráneo sin hallazgos relevantes, y se decide realizar punción lumbar con presión de apertura de $30 \mathrm{~cm}$ de agua con pleocitosis neutrofílica (317 leucocitos/mL, N 95\%), hipoglucorraquia (7 mg/dL)) e hiperproteinorraquia (444.09 $\mathrm{mg} / \mathrm{dL}$ ), motivo por el cual se decidió inicio de terapia empírica con vancomicina y cefepime bajo sospecha de meningitis bacteriana, se continuó con tratamiento antituberculoso.

Para el día siete de evolución se objetiva mejoría clínica importante dada por ausencia de disnea y fiebre, con persistencia de somnolencia, para este día se recibe el reporte de patología de cavidad oral con coloración de hematoxilina eosina con evidencia de dos lesiones granulomatosas con infiltrado linfocítico perilesional (Figura 3), basados en estos hallazgos se realizan coloración de Ziehl-Neelsen la cual evidenció bacilos ácido alcohol resistentes (Figura 4) compatibles con tuberculosis de cavidad oral.

Además, se realizó estudio de PCR en muestra de patología con evidencia de Mycobacterium tuberculosis, por lo cual se

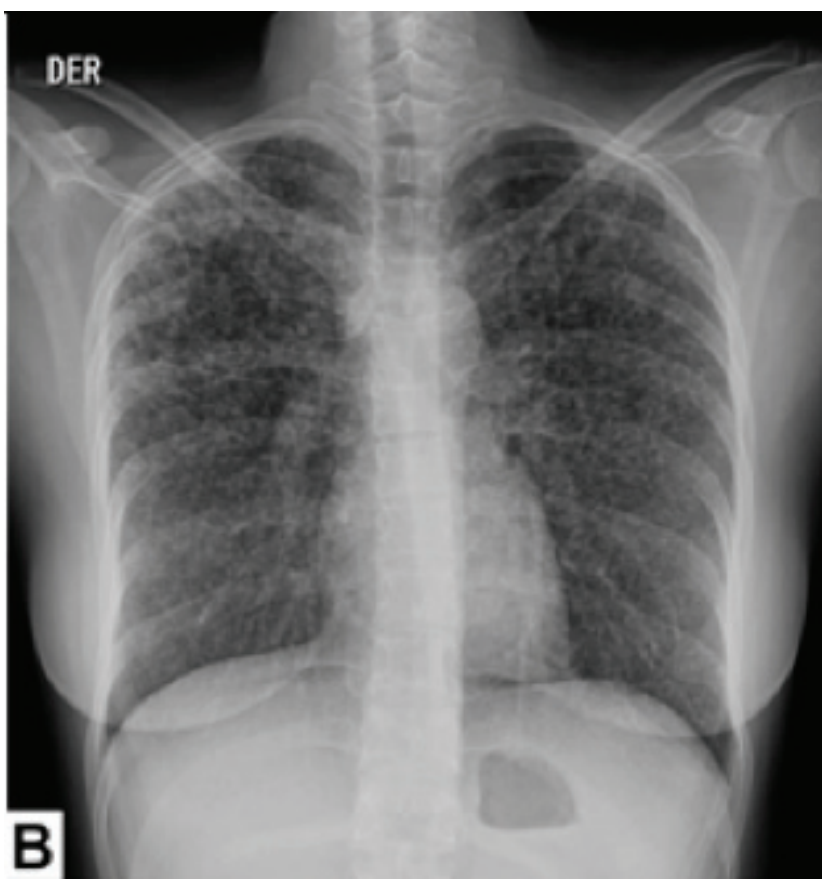

Figura 2. Radiografía de tórax: Proyección PA. Se muestran opacidades. 


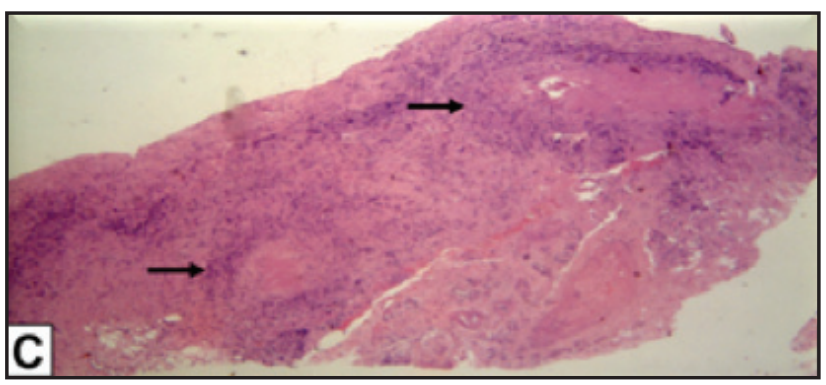

Figura 3. Coloración de HE x $10 \mathrm{X}$ con evidencia de dos lesiones granulomatosas con infiltrado linfocitico perilesional.

desescala tratamiento antibiótico (vancomicina - cefepime) continuando con tratamiento antituberculoso exclusivo.

Durante el día 24 de su estancia hospitalaria se recibe cultivo de líquido cefalorraquídeo en medio sólido de Lowenstein Jensen confirmando la infección antes documentada en bloque de patología.

Se considera como diagnóstico final tuberculosis de cavidad oral con diseminación pulmonar y meníngea.

Durante la evolución se objetiva mejoría clínica, dada por la ausencia de respuesta inflamatoria sistémica. Dentro de los estudios de seguimiento a las cuatro semanas de hospitalización se documentan transaminasas elevadas cinco veces por encima del límite de referencia por lo cual se considera hepatotoxicidad y se suspende el tratamiento antituberculoso iniciando un esquema de segunda línea con linezolid, amikacina, amoxicilina y etambutol.

La paciente persiste con somnolencia y postración en cama, por lo cual es llevada a estudio de tomografía cerebral simple mostrando abombamiento del tercer ventrículo y astas temporales, reducción del espacio subaracnoideo periférico, línea media conservada y borramiento de los surcos cerebrales, llamando la atención lesiones hiperdensas parietales que podrían corresponder a lesiones por tuberculosis (tuberculomas). Es valorada por el servicio de neurocirugía quienes consideran hidrocefalia con requerimiento inmediato de derivación ventriculoperitoneal, la cual se realiza en la semana 11 con mejoría notoria del estado neurológico.

Con un mes de tratamiento antituberculoso de segunda línea la hepatotoxicidad se resuelve reiniciando paulatinamente el esquema de primera línea con el cual la evolución clínica se torna hacia la mejoría al igual que el estado neurológico y la ausencia de respuesta inflamatoria sistémica.

Después de cuatro meses de hospitalización la paciente egresa con tratamiento ambulatorio completando en su seguimiento seis meses de terapia efectiva, evidenciándose como única secuela tinitus izquierdo persistente con imágenes de tórax y cerebral sin secuelas patológicas.

\section{Discusión}

La tuberculosis es una enfermedad infecciosa crónica causada por Mycobacterium tuberculosis, durante el año 2015 se documentó un número mundial estimado de nuevos casos de 10,4 millones ${ }^{2}$, la tuberculosis extrapulmonar da

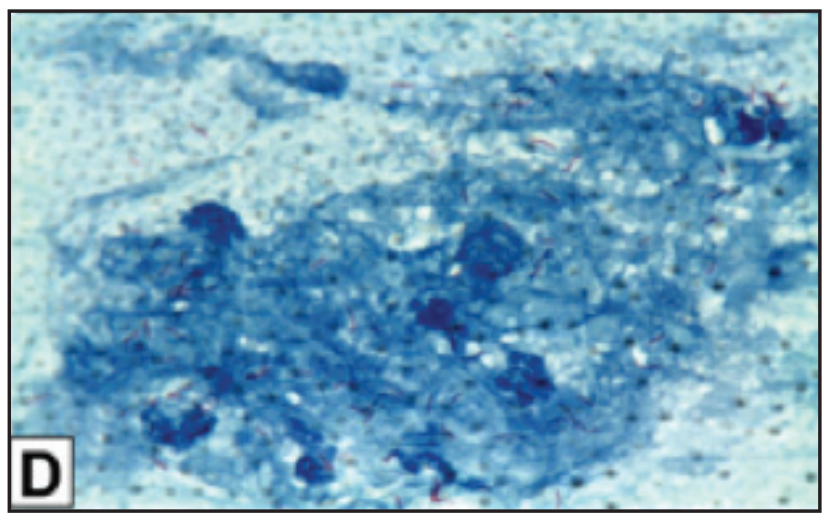

Figura 4. Coloración de ZN x 40X se observan bacilos acido alcohol resistente.

cuenta de aproximadamente $25 \%$ de todos los casos, de los cuales $10-35 \%$ son detectados en cabeza y cuello (3).

Las lesiones tuberculosas primarias en cavidad oral son extremadamente raras, debido a la integridad de la mucosa oral, la limpieza permanente por la saliva y la ausencia de folículos linfoides en dicha zona (4); de esta manera la presentación más típica es secundaria representando el $0.05-0.5 \%$ de los casos de tuberculosis extrapulmonar en algunas series $(5,6)$.

En la mayoría de los casos la tuberculosis primaria de cavidad oral ocurre en niños y se presenta en la lengua como sitio principal, se caracteriza por ausencia de dolor y suele acompañarse por adenopatías cervicales (6) como en nuestro caso, de otra parte las lesiones en cavidad oral que son de etiología secundaria provienen por diseminación hematógena o linfática y el órgano primario corresponde al pulmón, estas úlceras generalmente son dolorosas y no se acompañan de adenopatías regionales (7) en la mayoría de los casos.

Vale la pena mencionar que los factores de riesgo para los dos tipos de presentación se corresponden con inmunodeficiencia (diabetes, alcoholismo, estados postrasplante, HIV, uso prolongado de esteroides) tabaco, pobre higiene oral, periodontitis y trauma en cavidad oral incluidas las exodoncias (8) como ocurrió en nuestra paciente.

El diagnóstico diferencial incluye carcinoma escamocelular, otras enfermedades granulomatosas como sífilis, poliangeitis con granulomatosis (Wegener), actinomicosis, sarcoidosis, enfermedad de Crohn, reacciones a cuerpo extraño y ulceras traumáticas $(9,10)$.

Este caso representa un caso atípico de una mujer con una ulcera crónica en cavidad oral asociado a pérdida de peso y síntomas constitucionales en la cual el único factor de riesgo identificado fue la exodoncia realizada que se correspondió con el inicio del cuadro clínico descrito.

El diagnóstico final de tuberculosis primaria de cavidad oral con diseminación pulmonar y meníngea se logró establecer por estudio de patología y PCR en bloque histológico de cavidad oral como con cultivo de líquido cefalorraquídeo.

De esta manera se describe un caso de baja prevalencia y presentación atípica de tuberculosis en cavidad oral con 
diseminación pulmonar y meníngea, que le dará al lector algunas herramientas clínicas para sospechar dicha entidad en pacientes que se presenten con úlceras crónicas en cavidad oral.

\section{Referencias}

1. Pankaj J, Isha J. Oral Manifestations of Tuberculosis: Step towards Early Diagnosis. J Clin Diagn Resear. 2014 Dec, Vol-8 (12): ZE18-ZE21.

2. Rafael P, Víctor A, Pedro R, Danay C. Tuberculosis pulmonar y lingual. Presentación de un caso. Rev Col Gastroenterol / 29 (2): 2014.

3. World Health Organization. WHO Report Global Tuberculosis Control 2015. Geneva: World Health Organization.

4. Kakisi OK, Kechagia AS, Kakisis IK, et al. Tuberculosis of theoral cavity: a systematic review. Eur J Oral Sci. 2010; (118):103-9.3.

5. Al-Rikabi AC, Arafah MA. Tuberculosis of the tongue clinically masquerading as a neoplasm: a case report and literature review. Oman Med J, 2011, 26 (4): 267-268.

6. Iype EM, Ramdas K, Pandey M, Jayasree K, Thomas G, Sebastian P, Nair MK. Primary tuberculosis of the tongue: report of three.

7. Ramírez A, Anaya G, González R, Imelda M, Gómez J, Esquivel L, Reyes E, et al. Ulcera lingual como signo único de infección recurrente por micobacteria en un paciente con VIH/SIDA. Med Oral Patol Oral Cir Bucal 2005; (10): 109-14.

8. Ebenezer J, Samuel R, Mathew GC, et al. Primary oral tuberculosis: report of two cases. Indian J Dent Res 2006; (17): 41-4.

9. Kakisi O, Kechagia A, Kakisis I et al. Tuberculosis of the oral cavity - a systematic review. Eur J Oral Sci 2010; (118): 103-9.

10. Ewa K, Elżbieta S. Tuberculosis of the oral cavity: an uncommon but still a live issue. Postep Derm Alergol 2015; XXXII (4): 302-306.

11. Alawi F. Granulomatous diseases of the oral tissues: differential diagnosis and update. Dent Clin N Am 2005; (49): 203-21.

12.Zoulounis L, Lairidis N, et al. Primary tuberculosis of the oral cavity. Oral Surg Oral Med Oral Pathol. 1991; (72): 712-15. 